\title{
MUJER ANDINA Y MEMORIA DE TRADICIÓN ORAL EN RETABLO DE JULIÁN PÉREZ HUARANCCA ${ }^{1}$
}

\author{
Edith PÉREZ OROZCO \\ Universidad Nacional Mayor de San Marcos \\ eperezo@unmsm.edu.pe
}

\section{RESUMEN}

Nuestra investigación apuesta por un acercamiento desde la memoria para comprender las causas y consecuencias del conflicto armado en los ochenta. La categoría de memoria nos permitirá determinar la organización y la interpretación a nivel de historia y discurso en Retablo (2004), de Julián Pérez Huarancca. La novela refiere las luchas y conflictos de la memoria que dan cuenta de los procesos sociales e históricos que van desde finales del siglo XIX hasta finales del siglo XX en la ciudad de Ayacucho. Así, en la novela la diégesis muestra diversas imágenes-escenas, mosaico de testimonios en simultáneos y complementarios donde los narradores y protagonistas narran historias entrelazadas en un tiempo cíclico para proporcionar recuerdos sobre la violencia desatada en Ayacucho. En este presente artículo, estudiamos e interpretamos la representación de la memoria de tradición oral desde la configuración de la femeneidad andina, específicamente, en Escolástica, ${ }^{2}$ madre de la familia Medina Huarcaya; así se podrá comprender su rol como matriz generadora de la memoria de tradición oral; y será quien lleve a cabo la defensa, la confrontación y la negociación de la identidad andina en la novela Retablo.

\section{PALABRAS CLAVE}

Memoria, tradición oral, femeneidad y mundo andino.

\section{ANDEAN WOMAN AND ORAL TRADITION MEMORY IN RETABLO DE JULIÁN PÉREZ HUARANCCA}

\section{ABSTRACT}

Our research is committed to an approach from memory to understand the causes and consequences of armed conflict. The memory variable will allow us to determine the organization and interpretation at the level of history and discourse in Retablo. The novel refers to the struggles and conflicts of memory that account for the social and historical processes that go from the late nineteenth century to the end of the twentieth century in the city of Ayacucho. Thus, in the novel the diegesis shows various imagesscenes, a mosaic of simultaneous and complementary testimonies where the narrators and protagonists narrate stories intertwined in a cyclical time to provide memories of the violence unleashed in Ayacucho.

In this present article, we study and interpret the representation of oral tradition memory

1 El presente artículo es parte de la tesis "Memoria crítica y crítica de la memoria en Retablo, de Julián Pérez Huarancca", para optar el grado de Magíster en Literatura Peruana y Latinoamericana por la Universidad Nacional Mayor de San Marcos.

2 Otro artículo merece el análisis textual de la memoria de tradición oral en protagonistas como Mama Auli, tía Petronila, Clavelina Contreras y Adelaida. En todo caso, hemos estudiado y ampliado nuestra propuesta en la tesis antes mencionada. 
from the configuration of the Andean femininity, specifically, in Scholastica, mother of the Medina Huarcaya family; thus, its role as a generating matrix can be understood from the memory of oral tradition that supports the resistance, confrontation and negotiation of the Andean identity in the novel Retablo written by Julián Pérez Huarancca.

\section{KEY WORDS}

Memory, oral tradition, feminity and Andean World.

Recibido: 22/03/2019

Aprobado: 17/05/2019

\section{ANTECEDENTES} etablo de Julián Pérez Huarancca obtuvo el Premio Nacional de Novela Federico Villarreal ${ }^{3}$ en el 2003 y se publicó un año después (2004) por la Editorial de la Universidad Nacional Federico Villarreal. La novela se publica por segunda vez en el sello de la Editorial San Marcos en el 2006. La tercera edición también sale a la luz por la misma casa editorial en el 2008. Ya en el 2018, en el mes de setiembre, se publica una cuarta edición a cargo de la compañía editorial Random Penguin House de Lima para su colección Debolsillo4. Sobre esta reciente y cuarta edición, en la página web de Megustaleer se anuncia que Retablo (2018) es una obra intensa de "penetrante retrato psíquico y ético", que trata sobre el conflicto armado interno. La historia se narra "desde dentro", "desde sus raíces familiares", representando una "hecatombe nacional".

González Vigil (2007) señala que Retablo es una excelente novela; y que Fuego y ocaso, novela elogiada por Washigton Delgado, es el antecedente ${ }^{5}$ de aquella, pues esta trata sobre un sujeto en desplazamiento, en búsqueda de la verdad y la reconciliación.

Según Oswaldo Reynoso (2014), Retablo es una de las novelas de la violencia de los últimos años, que se caracteriza por utilizar el lenguaje "como un instrumento de belleza" y presentar de manera profunda su estructura. Esta es una de las novelas ${ }^{6}$ que nos permite ver "el infierno de esa época y nos señala el camino a un paraíso" (p.15).

La crítica literaria ubica la narrativa de Julián Pérez Huarancca (Ayacucho, 1954) dentro

3 El jurado estuvo compuesto por Miguel Gutiérrez, Carlos Eduardo Zavaleta y Ricardo González Vigil.

4 De hecho, cita el comentario de Ricardo González Vigil realizado en el periódico El Comercio (2007).

5 De la misma manera, Mark Cox (2009) plantea que Fuego y Ocaso representa la complejidad del conflicto y las consecuencias existenciales y confusas de sus personajes. Se describe las acciones de destrucción y abusos de las fuerzas armadas y acciones crueles de los subversivos. Así el pueblo de Pumaranra se halla entre estas dos acciones que causan caos. Así don Faustino Melgar / Víctor Medina huye del pueblo y se inscribe en la subversión. Este personaje representa una doble identidad. Por otro lado, se critica a la prensa peruana por no confrontar y demostrar evidencias o una "visión verídica" sobre los hechos de la violencia política; en todo caso, se expone la "cuestión de la confusión" en sus personajes, performances y actuaciones. Se confrontan las dicotomías de la verdad y la mentira. En suma, se cuestiona la verdad sobre las versiones de la guerra subversiva y su manipulación en los medios de comunicación.

6 Óscar Colchado y su libro emblemático, Rosa Cuchillo; Ese camino existe, de Fernando Cueto; La noche y sus aullidos, de Sócrates Zuzunaga y Candela quema luceros, de Félix Huamán Cabrera son las otras novelas mencionadas por Reynoso. 
de la denominada narrativa andina ${ }^{7}$, literatura de la violencia ${ }^{8}$ o narrativa post CVR $^{9}$ (Informe final de la Comisión de la Verdad y Reconciliación) entre otras. Escritor andino culturalmente cercano a los actores y víctimas del conflicto armado, sensibilizado por la tragedia, heredero de la tradición indigenista (José María Arguedas y Ciro Alegría, específicamente), quien representa el drama del conflicto armado en Ayacucho. En esta novela los sujetos andinos se hallaban entre dos fuegos desatados por grupos subversivos y las fuerzas represivas del Estado.

La prolífica producción narrativa de Julián Pérez Huarancca representa el contexto ayacuchano en un antes, durante y después de desatada la violencia política. Sus textos ficcionales ${ }^{10}$ abarcan desde relatos como Transeúntes (1988) hasta novelas como Anamorfosis (2017) ${ }^{11}$ que acechan, escudriñan, demandan, discuten y cercan a la violencia política desde la memoria.

A partir de la narrativa de Julián Pérez y desde las primeras ediciones, Retablo concita el interés de la crítica literaria periodística y académica, de escritores, poetas, editores, ensayistas e investigadores académicos. Estos últimos, han reportado y expuesto, en certámenes literarios, en publicaciones literarias y humanísticas, y en disertaciones universitarias sus propuestas de lecturas. La novela en estudio ha sido leída desde diversas propuestas ya ideológica, ética, política, estético-formal y de hecho la temática que van desde la representación de la violencia política hasta el contradiscurso de la demonización.

Antes de iniciar el análisis, valga recordar, brevemente, los ítems principales de la diégesis en Retablo. Dicha novela trata sobre la interacción y diálogo de múltiples voces y memorias. Presenta tres tipos de narradores (personaje, testigo y omnisciente), cuenta con la representación de un mosaico de testimonios, con diversos puntos de vista (polifonía) que se complementan de manera simultánea, multitemporal y paralela. La novela, cuya estructura externa consta de 36 capítulos, inicia con el retorno de Manuel Jesús hacia Ayacucho, quien va evocando sus recuerdos de infancia, adolescencia y juventud. Desentierra sus recuerdos y los integra con otros testimonios e historias ${ }^{12}$ con la intención de comprender el porqué

Ver: Juan Alberto Osorio (2002) y Dorian Espezúa (2006).

Mark R. Cox $(2003,2004)$.

Faverón (2006; 2007; 2008), Paolo de Lima (2006) y Paul Asto (2018).

10 Relatos como los de Transeúntes (1988), Tikanka (1989), Los dominios del fuego (1995, Premio Concurso de Cuento Asociación Cultural Peruano Japonesa), Papel de viento (2000), Piel de utopía y otros cuentos (2011); novelas como Fuego y ocaso (1998), Retablo (2004, Premio Nacional de Novela de la Universidad Nacional Federico Villarreal), El fantasma que te desgarra (2008), Resto que no cesa de insistir (2011), Criba (2014, Premio Copé de Novela ) y Anamorfosis (2017, Premio Novela Corta Julio Ramón Ribeyro) conforman su vasta producción. Debemos incluir los textos de la colección Runasimi, edición bilingüe-española publicada por la editorial San Marcos, en donde Julián Pérez y Dante Castro escriben el libro de cuentos titulado Hijo del viento. El ángel de las islas (2010); y Julián Pérez y Washington Córdova Huamán, el volumen de cuentos La muchacha de copiosa cabellera. Historia de los amantes (2010).

11 Esta última ganadora del XX Premio Novela Corta Julio Ramón Ribeyro organizado por el Banco Central de Reserva del Perú. El jurado estuvo conformado por Francesca Denegri, Alonso Cueto, Abelardo Oquendo, Mirko Lauer y Marcel Velásquez.

12 Según el ensayista y escritor Miguel Gutiérrez (2007), la novela refiere cuatro historias: 1) la historia familiar de los Medina Huarcaya; 2) la historia del pueblo andino de Pumaranra; 3) la historia de la crisis existencial de Manuel Jesús Medina, además es el narrador principal y 4) la historia sobre la guerra subversiva conducida por Grimaldo Medina. 
de la muerte de su abuelo (Gregorio Sacsara); cuáles fueron las causales para que su padre (Néstor Medina) sea torturado, humillado y detenido en la prisión entre seis a siete años; explicar el porqué las comunidades de Lucanamarca y Pumaranra se enfrentan años tras año; conocer los argumentos legales y sociales para llevarse a cabo la expropiación del cerro de sal de Urankancha a favor de los hacendados; evidenciar la intencionalidad de Antonio Fernández como figura representativa e incitador de la violencia política en la comunidad de Pumaranra; explorar el antes, durante y después del contexto de la violencia política en Ayacucho; indagar y encontrar el cuerpo insepulto de su hermano desaparecido (Grimaldo Medina); y resolver los motivos de su crisis existencial e identitaria.

\section{MEMORIA DE TRADICIÓN ORAL}

La presencia de la tradición oral o memoria de tradición oral andina es importante a lo largo de la novela Retablo. La memoria de tradición oral es iniciada por Néstor Medina ${ }^{13}$, continuada por Escolástica, la tía Auli, Grimaldo y Manuel Jesús quienes reconstruyen las escenas más desgarradoras sobre su familia y su comunidad. Esta memoria es un tema recurrente en Retablo. A continuación explicaremos de qué manera se trabaja esta memoria en la novela en estudio.

La tradición oral es un pensamiento totalizador relacionado a la memoria colectiva ${ }^{14}$. Reproduce el pasado y expone su propia racionalidad. Refuerza, reafirma y asegura la identidad y la reproducción de la oralidad. Se representan universos simbólicos codificados en la discursividad, con diversos lenguajes y performances.

Así la tradición oral y la memoria colectiva mantienen una relación dialéctica que comprende la historia oral y la historia de vida. Los sujetos actualizan el recuerdo a través de relatos fantásticos, míticos, afectivos e historias de vida. Además de los cantos, danzas, rituales del sistema de vida comunal, ente otros ${ }^{15}$. Se suelen trasmitir de generación en generación, los relatos que presentan la forma de ver, percibir y conducirse en el mundo de la comunidad y la pertenencia a la identidad.

Según Jorge Terán (2008), para referirnos a la tradición oral se debe considerar la materia básica, el núcleo que hace posible la transmisión. Se refiere a la oralidad como un sistema comunicativo y una forma particular de organizar la cultura. Y esta se caracteriza por mantener el contacto oral, único e irrepetible. Pertenece a un territorio y tiempo determinado. Asociado al retorno de la voz y la performance en el que se fija la episteme y la historia de una cultura. La oralidad se actualiza y recupera la memoria por medio de la materialización o concretización de la tradición oral.

13 "Se convertía en un excelente contador de hechos pretéritos, aunque no era tanto una reiteración de lo mismo" (p.40).

14 Según, Espino (2010) la tradición oral relata tensiones de violencia registradas desde la invasión española y aún mantiene el significado originario y su aura sublevante.

15 Existe una gama de discurso sobre la tradición oral; no se reduce a factores tradicionales como mitos, cuentos, cantos, adivinanzas, sino también se presentan como relatos, proverbios, dichos, sentencias, formas ceremoniales, grupos de parentesco, reuniones comunales y la inclusión de narraciones de los sueños y asuntos medicinales. Discursos que asumen la colectividad y el actuar de lo cotidiano. Además se presentan con las formas de historia oral e historia de vida. 
De ese modo, la tradición oral recupera y mantiene la memoria individual y colectiva; expone el aprendizaje de las tradiciones, sus normas sociales y asegura la reproducción del pensamiento social e imaginario colectivo por medio de la transmisión de mitos, cantos, leyendas, relatos, adivinanzas, etc. Debemos considerarla como vehículo que refuerza la identidad, pues se halla ligada a factores intencionales, afectivos y socioculturales. La tradición oral se actualiza en las narraciones orales por medio de la interacción oral y corporal.

Según Gonzalo Espino Relucé (2010), los conceptos básicos y elementales de la tradición oral son los siguientes: 1) el tiempo de la narración se resemantiza. 2) Las marcas de la voz se transmiten de padres a hijos, lo que podría generar una continuidad generacional o su detención. 3) La forma oral representa una comunidad cultural: pertenencia e identidad que corresponden a las fuerzas íntimas de la colectividad. 4) Su condición popular hace que la literatura oral convoque a los integrantes de la comunidad. 5) Es un evento único e irrepetible entre el hablante y el oyente. 6) Toda interpretación de la forma oral será única por medio de la voz.

Además, Gonzalo Espino (2010) propone la existencia de cinco marcas de voz: 1) la relación de quién narra o dice la historia y quién(es) escucha(n) o sigue(n) la historia. Para eso, es necesario comprender la existencia de un contrato tácito sobre el desarrollo del acto de narrar; que puede conmover, emocionar, entretener o lograr afectar a su público. A veces, el público es restringido y se narran los hechos solo a los pertenecientes al "runakuna". Asimismo 2) se desarrolla con normalidad la relación dialógica entre los hablantes y los oyentes; existe un acuerdo tácito sobre el manejo del tiempo, ya que es importante considerar las diferencias de los contextos del qué se trata y desde dónde se narra. Por eso, esta marca permite reconocer y diferenciar el manejo del tiempo dentro de la narración. También 3) el espacio determina la dimensión de producción; y se selecciona el uso de materiales tecnológicos para su registro (grabación, letras, video, etc.). Del mismo modo, 4) se utiliza la performance del cuerpo y la voz, ya que se transmite de voz a voz, de cuerpo a cuerpo, de una identidad a otra que logra comunicarse de generación en generación, es decir, se lleva a cabo la interacción comunicativa cara a cara ${ }^{16} .5$ ) La narración oral genera el placer de narrar; el espacio es propicio para transmitir, recrear y producir narraciones que "vuelve[n] con el recuerdo fecundo que aproxima a los propios" (Espino, 2010, p. 39).

\subsection{Transmisión de la memoria}

La transmisión de la memoria obedece a tres reglas. Uno, utiliza los recuerdos para adaptarse a modalidades acorde a la intencionalidad e iniciativa personal, organizada o institucionalizada. Dos, según sea la transmisión podría presentarse de manera espontánea, automática, uniforme y ser homogénea. Y tres, la transmisión se reconstruye a partir de la memoria individual, colectiva e histórica.

16 Para iniciar nuestro planteamiento seguiremos a John B. Thompson (1998) quien propone tres tipos de interacción en la comunicación: 1) cara a cara, 2) mediática, y 3) casi-interacción mediática. En la interacción de cara a cara, los personajes comparten un mismo sistema de referencia, tiempo espacial y están frente a frente determinados por una relación dialógica. En las conversaciones y diálogos afloran las sensibilidades, la memoria, el olvido y los arrepentimientos. 


\section{Tipos de transmisión}

Son dos tipos de transmisión:

1) Las instituciones de la memoria garantizan la conservación y la transmisión de la memoria. Establecen hechos que enriquecen la memoria colectiva a través de la investigación ${ }^{17}$, la educación, los medios de comunicación, los archivos y las bibliotecas. Estos dos últimos son los lugares de la memoria, depósitos legales que aspiran conservar la memoria y a acrecentar la información. (Sansón, 2007). Por un lado, la biblioteca ${ }^{18}$ es un edificio que colecciona diversas informaciones sobre diversas épocas para la memoria de los lectores. Por el otro, los archivos son productos o medios relacionados a la vida jurídica. Se utilizan, además, a los archivos "orales" (testimonios judiciales) para llenar de manera ostensible los vacíos dejados por los archivos escritos para cumplir con la necesidad de ejercicio y prueba de los derechos de las personas naturales o jurídicas, públicas o privadas.

2) La tradición oral ${ }^{19}$ se produce de manera espontánea por medio de la memoria individual o privada, se activa y halla constituida por los recuerdos a) personales; b) familiares, de carácter anecdótico, con evocación de vivencias intensas, de encuentros decisivos, de episodios que dejan un recuerdo perdurable; $y$, finalmente, c) se trata sobre el acontecimiento de la historia común, y de haber sido testigo directo de los hechos de lo "vivido y sufrido". A partir de estos tres niveles se llevan a cabo los recuerdos de los acontecimientos como testimonio personal. Así la memoria a partir de la tradición oral integra a los sujetos sociales. También se incluyen testimonios indirectos, de historia de vidas de sujetos de la comunidad, además de ubicar narraciones de seres fabulosos y míticos propuesta como historia oral (Rivera Cusicanqui, 1997). Por tanto, se evidencia la tradición oral como historia de vida e historia oral.

En Retablo la memoria de tradición oral se asocia a la marcas de voz y se hace efectiva en las voces de los personajes femeninos sin desmerecer, claro está, los discursos de Néstor Medina y Grimaldo Medina. A continuación nos detenemos a analizar e interpretar el desarrollo de la memoria de tradición oral dentro de la configuración de la femeneidad andina; luego, nos detenemos, específicamente, en el caso de Escolástica.

\subsection{Mujer y la memoria}

En la novela, la mujer andina es imprescindible para comprender la multiplicidad de memorias representadas (autobiográfica, histórica, melancólica, del duelo,

17 Tanto la investigación como la educación se hallan desfasados y simplificados por la memoria institucional. Aunque se hallan hechos incompletos, se favorece a los vencedores, olvida retazos de la historia e ignora a ciertos grupos (pobres, mujeres y niños).

18 Dentro de este punto, se incluye la función de la biblioteca, la cual se presenta en tres fases: almacenamiento, memorización clasificada y remembranza. En otras palabras, adquiere, clasifica y consulta.

19 Aunque según René Remond (2007) presenta dos debilidades: 1) es fragmentaria y se lleva a cabo por la selección previa a partir de la subjetividad y su selección es aleatoria, sin contar con la exigencia del conocimiento histórico. Por eso "resulta que esta forma de transmisión no es lo suficientemente segura como para que se le pueda confiar la comunicación de la memoria del pasado de una generación a otra" (p. 71); y 2) el silencio de los testigos muchas veces dificulta la comunicación de la experiencia creando un obstáculo de la incomunicabilidad. Sin embargo, sugiere que el silencio también comunica y denuncia hechos. 
entre otros). Su presencia reconfigura y reconstruye las memorias a través de 1) su presencia como guía y soporte de la memoria del personaje principal (Manuel Jesús), también como 2) la fabuladora y narradora de tradición oral (historias de vida e historia oral); y como 3) productora de testimonios contados y cantados. En ella, se articula la memoria autobiográfica o individual y la memoria colectiva. Tenemos a los personajes representativos como Escolástica, Mama Auli, Adelaida, tía Petronila y Clavelina Contreras. Hay una fusión entre la memoria íntima y el registro testimonial asociada a las narraciones testimoniales e históricas en la voz de los personajes. En palabras de Silvia Rivera Cusicanqui (2006) es la mujer que como madre e hija logra comunicarse y ser extraordinaria narradora ${ }^{20}$ dentro del espacio privado (familia) y del espacio público (comunidad). Creadora de lenguajes y de símbolos capaz de seducir al "otro" y establecer pactos de reciprocidad y convivencia. En Retablo, su narración y testimonio se da a través de los narradores heterodiegéticos (narrador omnisciente) y homodiegéticos (narrador testigo) quienes ceden la palabra a sus protagonistas dentro de la diégesis.

Kemy Oyarzún (1998) plantea el criterio de etnografía pluralista, es decir, la subjetividad de la mujer en diálogo con otras identidades y colectividades. Se presenta el sujeto femenino móvil, plural y fluido. Al saber del autor del texto (Julián Pérez Huaranca) debemos reconocer su manera magistral de plantearnos esta novela heterogénea como una producción genérico-sexual con criterio histórico-mítico. Las protagonistas son mujeres andinas, sujetos marginales que representan la matriz del texto. Es imposible su "silencio", el orden simbólico es la voz de la protagonista. Así lo permite el narrador heterodiegético, el lenguaje en la construcción de la voz femenina. Según Oyarzùn este aspecto produce la ginocrítica heterogénea, que consiste en el descentramiento de los protagonistas femeninos a nivel micro y macro físico en una novela.

Así en Retablo, la mujer ayacuchana se presenta como esposa-madre, hermana, tía, amiga y amante que ilumina el sendero oscuro de la muerte, de la confusión y de la incertidumbre. Esta figura representativa intenta recrear los valores de la mujer heroína, luchadora, mujer Pachamama (Pajuelo, 2012) como la personificación de los sentimientos familiares, comunales y personales. Así, Julián Pérez incorpora las voces y conciencias femeninas en las reflexiones del componente femenino en un antes, durante y después del tiempo de la violencia política. Esta forma de construir a los personajes femeninos, de conocerlas y personificarlas, dice Kemy Oyarzún, se denomina la producción de la ginocrítica heterogénea que consiste en el descentramiento de los protagonistas a nivel micro y macro físico en el texto ficcional.

Retablo nos presenta la situación de crisis del proyecto de modernización en los Andes y desesencializa las prácticas de los gamonales Fausto Amorín (padre e hijo). Manuel Jesús es el protagonista; y a partir de su narración y focalización "mira" activamente la participación de complementariedad de las féminas para

20 Según Julián Pérez Huarancca fueron sus padres quienes influenciaron en la narración de tradición oral, pero fue su madre el prototipo para el personaje de Escolástica; es más "Recuerdo que cuando mis hermanos y yo éramos niños, en las noches, antes de dormir, oír de sus labios los innumerables relatos populares era nuestro placer favorito. [...] A mí me gustaba conversar con mi mamá, incluso varias de las historias que incluyo en Retablo me las contó ella. Yo diría que Retablo es casi su voz y eso se complementa con algo de la de mi padre, que tenía una ironía extraordinaria" (Tolentino, 2014, p. 2). 
dejarlas reclamar, gritar, testimoniar, denunciar, exponer sus vidas privadas y vidas comunales. De ese modo, se lleva a cabo la reapropiación de la subjetividad, expone la voz y episteme de la mujer andina ayacuchana. Pérez nos habilita el dialogismo genérico-sexual (participación en asuntos comunitarios o sociales); hay un referente femenino involucrado dentro de la situación de la representación a partir de la memoria textual.

En Retablo, la experiencia de la mujer en la diégesis habilita la polifonía simbólica e imaginaria de nuestras sociedades. Representa la práctica epistemológica, contestataria y legítima de la crítica de la memoria andina. De este modo, concentrarnos en Escolástica nos permite profundizar en su rol actancial como generadora y depositaria de la memoria de tradición oral. En el siguiente subcapítulo determinamos el rol de Escolástica dentro de la educación, como figura y guía de los recuerdos o memoria autobiográfica de Manuel Jesús, además de representar marcas de voz y ser quien conserva y narra la historia oral e historia de vida.

\subsection{Escolástica}

Escolástica Huarcaya es la madre del protagonista principal de la novela. Su nombre proviene del clasicismo griego (Escolástica). Julián Pérez dialoga con la poética griega y medieval. El término "Escolástico"21 designaba al maestro que enseñaba el trivium (gramática, retórica y dialéctica) y el quadrivium (aritmética, geometría, música y astronomía) o las artes liberales con la intención de construir un espíritu libre. Según Bobes Naves (1998) se organizaba, constituía el saber, el dominio de las palabras y las cosas en la que se difundía el pensamiento aristotélico.

Escolástica es consciente de conservar la memoria de tradición oral, pero también es prudente al remarcar la conservación de la memoria a través de la educación de sus hijos. Su nombre permite relacionar la memoria de tradición oral con el proyecto de educación occidental. Así, ella y Néstor inician el desarrollo del proyecto de educación en sus hijos: “...cuenta el hogar en la adquisición de una rara riqueza: que sus hijos conozcan el abecedario, de anverso y reverso. Que conozcan, mediante la escritura descifrada la historia, la geografía de la alegría y la filosofía de la felicidad" (p. 30).

Para ella, la única manera de cambiar la situación de la crisis social, política y económica de su familia y de su comunidad es enviar a sus hijos a educarse: la escuela. Lugar encargado de proyectos de transformación cultural, social, política. Además, este proyecto educativo orgánico, una herramienta imprescindible, ayudará a resolver los conflictos no solo para sus hijos, sino para Pumaranra. Así lo menciona Manuel Jesús: "No sé cuál habría sido la formación que tuvieron mi madre y tía; no sé de dónde les habría nacido esa preocupación visceral por ver a sus hijos con una preparación cultural de solvencia" (p. 194). Los hijos de Escolástica se establecieron en Huamanga y otros espacios andinos con la intención de orientarse hacia los cambios de la modernización, claro está, para alcanzar la modernidad

21 En Bobes Naves (1998), la escolástica se presenta en cuatro tiempos: 1) La preescolástica o renacimiento carolingio (siglo VIII-IX); 2) la primera Escolástica, 3) la alta Escolástica o Edad de Oro de la Escolástica (siglo IX-XII), y 4) la Escolástica tardía (siglo XV-XVI). 
andina. Para Escolástica la escuela es una herramienta que permitirá a sus hijos lanzarse "a la conquista del futuro y progreso" (Ames, 2012, p. 137).

Por otro lado, Manuel Jesús dentro de su intento por salir de la memoria melancólica y alcanzar la memoria del duelo invoca a su madre y hermana como acompañantes hacia su memoria, su pasado: "Mi madre y mi hermana. Ah, las dos mujeres que poblaban mis sueños y mis recuerdos en el territorio del desarraigo" (p. 20). Para ello, dentro de su retorno hacia Ayacucho, en su mente, las invoca como agentes y guías para el viaje o desplazamiento hacia la memoria autobiográfica y se desplaza de un tiempo a otro activando la memoria intersticial ${ }^{22}$ :

He venido, después de tanto tiempo, elegido por el espíritu de los ausentes, sediento, tornasolado. Esperanzas, mitos, cosmogonías de la progenie irredenta me han redimido a cambio de convertirme en buril de memoria [...] Por suerte tengo a mi madre y a mi hermana que me han de guiar de aquí a la quebrada andina de mi niñez, al crepúsculo serrano de bueyes, becerros, alfalfares y, sobre todo, a comprender el cataclismo que me arrancó de mi comarca (p.5).

En ese aspecto, Retablo dialoga con la categoría de amor cortés representada en los textos ficcionales de la Edad Media, Prerenacimiento y Renacimiento. El amor cortés, en el siglo XII, concebía a la mujer como un ser lleno de perfecciones y moralmente superior al hombre, quien refleja la suma belleza de Dios, ya que era muestra de su saber y poder. Se logró divinizarla, enaltecerla, su amor se forjaba como un fenómeno volitivo y libre ${ }^{23}$. Recordemos, por ejemplo, que Dante Alighieri consideraba a la mujer ideal como un ser inalcanzable, a quien se la venera y se lleva el culto mariano. En su "teología poética" Dante presentaba a Beatriz en La divina comedia como guía hacia el paraíso; similar a ello en Retablo, Escolástica y Marcelina guían en el desplazamiento hacia el pasado:

A los pocos minutos de tomar la pócima siento el cuerpo dispuesto para el sueño. Me viene un relajamiento placentero que busco afanosamente mi cama. Mi madre me deja recostado, habiéndome recomendado descansar todo lo que pueda. Pero si bien es cierto que mi cuerpo pide paz y sosiego, mi mente, en cambio, empieza a agitarse pretendiendo actualizar lo que fue de vida y relaciones humanas en esta vieja vivienda, muchos años atrás (p. 39).

La memoria perturbadora de Manuel Jesús es controlada; siempre y cuando sean las féminas quienes resguardan y guían sus recuerdos; pero la "vieja vivienda" o el lugar de la memoria activa los recuerdos; y Manuel Jesús siente el descontrol de la memoria melancólica y lo perturba.

Finalmente, Escolástica simultáneamente lleva a cabo la presencia de las marcas de la tradición oral: narra historias y la escuchan sus hijos, existe una relación dialógica

22 La memoria intersticial es una memoria que rompe el espacio, quiebra la frontera del tiempo para dirigirse del presente hacia el pasado (y viceversa), se desplaza y emplaza al sujeto migrante.

23 Según Aurelio González (1991), el amor cortés presentaba una corriente dinámica y compleja que presentaba las siguientes vertientes: a) exacerbación del estado, b) extremo de la contención o abstinencia, c) exitosamente literaria, y 4) realiza el acto carnal. Para el Siglo XII, los poetas la consideraban como la guía de la conducta y la guía en el saber con el afán enciclopedista y moralizante. 
entre los hablantes y oyentes, el espacio determinado desde dónde narrar es Pumaranra (Ayacucho); y en la dimensión de producción se utiliza la oralidad que es transmitida de manera oral y el uso de la performance corporal: cuerpo y voz.

La madre de los Medina desarrolla la memoria colectiva a través de la tradición oral. Como narradora proporciona información de dos tipos: historia de vida (sobre Néstor, Fausto Amorín, Clavelina Contreras) e historia oral de hechos míticos, leyendas e historia de seres fantásticos. Ambos mecanismos sistematizan la manera de concebir el mundo de la comunidad y su aspecto sociocultural de Pumaranra.

Así, las tradiciones orales son transmitidas en formas de a) relatos en veladas familiares (Escolástica), b) relatos en veladas infantiles (Escolástica), c) conversaciones (Escolástica), d) confidencias entre madre e hijos (Escolástica, Grimaldo, Manuel Jesús y Marcelina), entre sobrinos y tías (Mama Auli, la tía Petronila y Ricardo), entre amantes (Adelaida), y e) cantos (Clavelina). Los temas recurrentes se acercan a los testimonios de vida de Escolástica y de Néstor Medina; la muerte del abuelo Gregorio Medina; y la desaparición de Grimaldo. Así se fragmenta el carácter unilateral de la memoria histórica oficial y se usan las tradiciones orales: historia de vida e historias orales (leyendas, mitos, cantos, adivinanzas) para denunciar las injusticias. Sin duda los testimonios familiares "son el testimonio desde donde se condensa y reordena la épica popular. La gesta contada y vivida adquiere verosimilitud en la memoria del pueblo gracias al narrador o cuentero que tenemos siempre en la familia" (Espino Relucé, 2003, p. 63). Saberes que facilitan el dominio y continuidad de la vida familiar y comunal; y el entendimiento del contexto sociocultural. A continuación, analizamos e interpretamos el desarrollo de la historia de vida e historia oral en la memoria de Escolástica.

\subsubsection{Historia oral y de vida}

La historia de vida se organiza a partir del recuerdo de las secuencias fijas de una experiencia temporal lineal y cíclica. El recuerdo de una individualidad de Escolástica narrando los hechos sucedidos a Néstor ${ }^{24}$ el día de su boda, la matanza de pumaranrinos en plena Fiesta de San Pedro, la violación y el asesinato de Clavelina Contreras (p.186). La tía Petronila narraba la historia de vida de su hermana (Escolástica), las carencias económicas que sufrían Escolástica y Néstor; y de ese modo logra que sus hijos cuenten con una educación que los proteja de las humillaciones e injusticias. Manuel Jesús reflexiona al respecto del sacrificio y carencias de sus padres y especula si fue la mejor opción, ya que su hermano desapareció y su padre jamás dejó de sentirse culpable:

Ellos dos, mis padres, eran capaces de venderse, como nos lo decía una y otra vez mi tía Petronila, al peor postor con tal de que a nosotros nunca no faltara lo que se requería para educarnos en la mismísima ciudad de Huamanga [....], me he preguntado qué hubiese sido de nosotros si mi madre y mi padre nos hubiesen simplemente abandonado sin educación ni nada, tan sólo encaminándonos a ser buenos campesinos.

24 Néstor, por su parte, narraba hechos sobre la muerte de su padre Gregorio y cómo escapó y prometió a su padre no humillarse de salir con vida (p. 324). 
Eso probablemente no hubiese significado que nuestro hogar perdiese a mi padre, debido a una muerte natural a sus ochenta y tantos años de vida, nada sustancial hubiese variado en cada uno de los hijos, pero tal vez hubiese sido otra la existencia de mi hermano, de mi par (p.195).

De hecho, Manuel Jesús narra la historia de vida de su padre, recurre a los testimonios de su madre; a los de su padre, a la de su hermano Grimaldo, tía Petronila y tía Auli. Veamos un ejemplo, el mismo narrador heterodiegético en el capítulo 29 en la que nos expone la narración que la madre realiza acerca de su primera visita a la ciudad de Huamanga:

Lo que más les gustaba era que ella les contase los esfuerzos del pasado, de sus Ilantos en ese terreno en que ahora, por fin, tenía siquiera una vivienda pobre, pero dejaba en blanco todo lo que los pequeños querían saber, con reiteración, respecto de cómo había encontrado la ciudad de Huamanga cuando llegó la primera vez (p. 283).

Escolástica es testigo de la información y es parte de su experiencia directa de las historias de vida. Puede sustentar utilizando evidencias de información: "vi", "estuve ahí". Gracias a su información se recogen testimonios de aspectos intencionales y éticos de la familia Medina Huarcaya:

Fue el infierno lo que se vivió esa tarde, hijos míos de mis entrañas, manchas de sangre coagulada se veían por doquier, y nuestros ojos cada vez más cerca del peligro, manchas de sangre allí donde estaban los caídos [...], mi Néstor, apresado, en manos de Fausto Amorín y las autoridades de Cangallo (p.191).

Según Manuel Jesús, Mama Escola se convierteen“la memoria lacerada de Pumaranra, sin ser pumaranrina de nacimiento pero pumaranrina al fin" (p. 140). Asume una posición crítica hacia la historia oficial. Vemos, por ejemplo, que Escolástica continúa con la narración sobre la funesta noche del 30 de junio. Confiesa a Grimaldo sobre el maltrato e injusticia cometidas hacia su padre por Fausto Amorín (hijo):

-Tal vez sería mejor que lo sepas... tienes que saberlo Grimaldo, para que mañana más tarde tendrás presente que es mejor no tener líos con quienes tienen riqueza. Tu padre, el personero, fue golpeado sin compasión, porque era el único que sabía rubricar una firma [...]. En medio de ese frío, los guardias civiles se encargaron de azotarlo con zurriago que sirve para amansar chúcaro, hasta dejarlo tirado en el suelo, desmayado y sin aliento, con surcos rojos y morados en sus espaldas. Que no lo mataron a él y a las demás autoridades no fue por compasión, sino porque simplemente les eran útiles vivos (p. 233).

Escolástica transmitía la historia de vida como relatos en las veladas familiares, infantiles, y veladas nocturnas ${ }^{25}$; además de hacer confidencias familiares para evitar sufrimientos e injusticias silenciadas por su padre y abuelo (Gregorio Sacsara):

Así lo sentían; por eso, sobre todo Escola, lloraba, se deshacía en lágrima cada vez que había movimiento de gente en revuelta, tanto en la ciudad como también 
reclamos en Pumaranra, pues los hijos de Néstor, y ella lo presentía, acaso tenían desde la raíz de sus abuelos un viejo contrato, una vieja palabra fiada a favor de los más humildes de Pumaranra o de otros lares que constituían lo más lejanos confines (p. 285).

Sin embargo, en el capítulo 29, el narrador heterodiegético insiste en exponer las preocupaciones y el temor de Escolástica, ya que las narraciones pueden activar las conciencias de sus hijos en búsqueda de venganza:

Escola sentía que las cosas ocurridas con Néstor tiempo atrás por andar encabezando gentíos, y referidas con énfasis en las noches después de la cena, en voz de servir de escarmiento más bien servía de acicate para el empeño de sus hijos en unirse y más a las aspiraciones de Pumaranra (p. 285).

Por otro lado, la historia oral pertenece a la memoria colectiva y es plural. El intérprete se adapta a la personalidad colectiva de la deixis "nosotros" como relator y protagonista de la historia. Se recogen tópicos y episodios públicos compartidos con la comunidad. Se resemantiza la oralidad, debido a los continuos olvidos y recreaciones. Se expone el tiempo cíclico en el que se mantienen los imaginarios sociales. Así la colectividad selecciona sus experiencias socioculturales.

En Retablo la historia oral se presenta como un "mecanismo interpretativo" acorde a su presente contextual. Escolástica narra eventos míticos y fantásticos. Contribuye y refuerza la conciencia ética de sus hijos e involucra la formación de la episteme andina ${ }^{26}$. Sus narraciones se inscriben en la representación y creencia en los personajes míticos andinos como condenados, amarus, cóndores, vacas sentimentales y árboles sensitivos, entre otros.

Es interesante comprender la presencia de los siguientes textos de tradición oral, de manera singular la historia oral: 1. del burrito moro que defendió a su ama y murió ante las maldades del diablo; 2 . cóndores que raptan doncellas andinas, y 3. los muchachos desobedientes convertidos en estrellas (en siete cabrillas del cielo):

...cuentos de aparecidos, del burrito moro que defendió a su ama murió ante las maldades del diablo, de cóndores que raptaban a las doncellas andinas, de muchachos desobedientes convertidos en las siete cabrillas del cielo; sin pretenderlo, llenaba la mente de sus hijos con las hilachas ardientes de los días del pasado oprobiosos, con el honor milenario ultrajado por rostros barbados, corazones de piedra y almas de lobos, que mancillaban aldeas andinas donde sí efectivamente, hay vacas sentimentales, hay árboles sensitivos, metiendo en el torrente de sus venas -sin desearlo y para propios pesares de años despuésodios, rencores imborrables, venganzas perentorias aplazadas para con los poderosos de allí, del más allá y de mucho más allá de los confines de la tierra " (p. 189).

26 Los hermanos Medina Huarcaya conservan y generan la memoria de tradición oral en dos aspectos: Grimaldo apertura una conciencia liberadora política; mientras que Manuel Jesús crea una conciencia humanística, pues es antropólogo y escritor: "No siento nostalgia sino felicidad y entiendo que fue mi padre quien, muy temprano, se encargó de perfilar en mí el gusto de conocer otras vidas, como en las novelas, con la diferencia de hacerlo a través del lenguaje oral" (p. 41). 
En el capítulo 22, el narrador autodiegético (narrador personaje), Manuel Jesús, nos hace partícipe de la narración completa del "burrito moro" y de los "tamboreros". La madre ya de edad relataba nuevamente las historia, así refiere Manuel Jesús que: "Y su felicidad la hace olvidar su reparo, su reticencia, sus inhibiciones, que empieza a contarme los relatos que sólo ella me los puede contar así como los cuenta" (p. 214). Escolástica madre longeva mantiene una memoria viva de la tradición oral, específicamente, la historia oral. En el segundo cuento trata sobre "los tamboreros". Escolástica antes de iniciar con la narración asevera: "Ustedes [Manuel Jesús, y Ricardo] no creen en los dichos de los antiguos, no creen que las cosas que les decimos son vividas, que han sido comprobadas en la existencia de las cosas" (p. 224). La tradición oral es presentada como un testimonio de "verdad".

En el mismo capítulo 22, estos dos cuentos se encuentran detallados. El narrador autodiegético nos hace partícipes de los relatos de su madre. De hecho se puede comprender cómo es que, efectivamente, influyó en Manuel Jesús cada uno de estos relatos. Se activa la capacidad de leer desde las historias orales, a las historias de la vida de Grimaldo, la suya y la de su madre; es decir, Manuel Jesús lee los sucesos de su vida a partir de los cuentos relatados por su madre. Así logró e interpretó lo que le sucedería a su hermano mayor:

$\mathrm{Ni}$ siquiera el lerdo, que allí seguía mordisqueando el pajonal impidió que yo pensara en los aparecidos que mi madre nos contaba todas las tardes de vacaciones en Pumaranra. No sé si fue premonición, pero esa vez imaginé que mi hermano se extraviaría en la noche lóbrega de Qocha, que un monstruo se lo comía. Ahora cierro los ojos y me instalo en ese preciso instante de hace veinte a treinta años, y quiero arrancarme el alma, como esa noche, por evitar que mi hermano, mi par, se me perdiera (p. 273).

O cuando, se enamoró por primera vez y comparó a su doncella con la bella mujer que se casó con el diablo:

Acababa la semana de fiesta yo me quedé turbado por siempre, no podía quitar de mi mente su figura, su mirada cargada de melancolía y de propuestas. Se me ocurría compararla con la muchacha bella que se casó con el diablo, en uno de los cuentos con que mi madre nos hizo pasar la niñez (71).

Así Escolástica narra historias a sus hijos para comprender y valorar la temporalidad actual. La historia oral descubre, expone las percepciones profundas y exalta la renovación de la identidad de sus hijos para legitimar la lucha de la memoria desde los márgenes y responder ¿qué pasó?, ¿quién lo hizo?, ¿quién tiene o tuvo la razón? (Rivera Cusicanqui, 1997).

De ese modo los hijos: Grimaldo y Manuel Jesús correlacionaban la realidad con los elementos míticos y fantásticos del mundo andino. Esa es la manera de ver y mirar el mundo andino moderno. 
En conclusión, la configuración de la femeneidad andina es un tema resaltante en la novela ${ }^{27}$. Las mujeres son valientes, respondonas, de cuerpos provocativos y respetados. La configuración de la mujer andina a través de su afecto, sensualidad y sexualidad evidencia ser la matriz en el que gira la trama de todo el texto. Los sujetos no son pasivos, ni exóticos, sino son sujetos que replican, riñen, se enfrentan al sistema (Mama Auli, Clavelita, Escolástica); mujeres que dentro del vínculo amoroso (Liz, Adelaida) buscan orientar, encausar a Manuel Jesús hacia la memoria de duelo; féminas (Marcelina y Escolástica) que guían a Manuel Jesús por el sendero de su memoria autobiográfica e intersticial y le permiten una oportunidad de definir y estabilizar su identidad.

Además, el análisis de la memoria de transmisión oral en Escolástica sobre lo ocurrido con Néstor, la muerte de Gregorio Sacsara y la funesta noche de junio que acabó con la población de Pumaranra son testimonio ${ }^{28}$ que se develan a través de la conversación que se presenta de dos maneras:a) desde una relación de exterioridad, el testigo narra hechos para alguien que escucha el relato (Grimaldo, Manuel Jesús y Marcelina); $\mathrm{y}$ b) desde la relación de interioridad, se lleva a cabo la determinación de la acción misma del sujeto en contar con los hechos como una prueba de convicción y evidencia. Así, la configuración de la memoria oral es prolífica. A través de la palabra oral 1) se reconstruye el árbol genealógico de la familia Medina Huarcaya, 2) se narra anécdotas sobre su abuelos, padres, tíos y tías, 3) se puede identificar a sus personajes con sus nombres y apellidos, 4) se refiere sobre sus vínculos amorosos entre Adelaida y Manuel Jesús; Liz y Grimaldo, 5) se alaba la belleza, inteligencia y sexualidad de las mujeres Pumaranrinas, 6) se cuentan los ritos, las costumbres de las comunidades, 7) conduce el ethos a los hijos de la familia Medina Huarcaya, 8) se relata el padecimiento de contar con la justicia y se expone el sufrimiento de la "gente humilde", finalmente, 9) en cada relato se puede observar el uso de semas complementarios no opuestos ni contrarios, sino semas como sueños y pesadillas, gusto y placer, defectos y virtudes, fuego y frío. Así comprendemos la relación entre mujer y memoria de tradición oral y la manera en que se representa en la novela.

\section{REFERENCIA BIBLIOGRÁFICA}

Ames, P. (2001). "¿La escuela es progreso? Antropología y educación en el Perú". En C. I. Degregori (ed.). No hay país más diverso. Compendio de Antropología peruana. Lima: Red para el Desarrollo de las Ciencias Sociales, pp. 346-391.

Asto, P. (2018)."Criba y la novela post CVR, o hacia una nueva vertiente en la novela sobre el conflicto armado interno". En Edith Pérez \&Jorge Terán, Cuadernos Urgentes Julián Pérez Huarancca (pp.143-167). Lima: Distopia Editores.

27 Es curioso que en Retablo ser wakcha no implica la pobreza y carencia social. Por ejemplo, Mama Auli no tiene hijos ni esposo; Néstor, huérfano de madre y padre, es adoptado por el pueblo de Pumaranra; Petronila y Escolástica, huérfanas de madre, logran conformar sus familias. Estos wakchas son respetados, queridos, estimados; y llegan a poseer rango social que les permite reciprocar con los "chutos" o indígenas de su comunidad. No se desligan de su ayllu y menos de su familia.

28 Según Marte Sánchez (2011), el término se presenta con diversas propuestas: como término jurídico (prueba jurídica; como término literario (género), función espiritual (religioso) o en sentido socio-histórico (declaración pública). 
Bobes, C.; Baamonde, G.; Cueto, M.; Frechilla, E.; Marful, I. (1998). Historia de la teoría literaria II. Trasmisores. Edad Media. Poética clasicistas: Madrid: Gredos.

Cabrera, J. (2014). Oswaldo Reynoso. En la creación es un acto donde ejerzo mi absoluta libertad y goce estético sexual. BuenSalvaje, 5, 14-15.

Cox, M. (2009) La verdad elusiva en Fuego y ocaso de Julián Pérez. En El azar inmóvil, $1,65-72$.

(2004). "Apuntes para el estudio de la narrativa peruana desde 1980 y la violencia política". En Mark Cox, Pachaticray (el mundo al revés) (pp.67-77). Lima. Editorial San Marcos.

(2003). Narrativa andina y la violencia política de los años ochenta y noventa. En Ángeles y demonios, № Cero, diciembre, pp. 84-85.

Espezúa, D. (2006). Zein Zorrilla. La novela andina: tres manifiestos. San Marcos, 25, pp. 404-409.

Espino, G. (2003). "Garúa y polvadera (polvareda), memoria de la tradición oral-Un intento de prólogo a las actas del Seminario Tradición Oral-". En Gonzalo Espino (Comp.), Tradición oral, culturas peruana-Una invitación al debate- (pp. 15-24). Lima: Fondo Editorial Universidad Nacional Mayor de San Marcos. Editores.

(2010). La literatura oral o la literatura de tradición oral. Lima: Pakarina

González, A. (1991). “De amor y matrimonio en la Europa medieval. Aproximaciones al amor cortés". En Concepción Company, Amor y Cultura en la Edad Media (pp.29-42). México: Universidad Nacional Autónoma de México.

González, R. (2007). Nace un novelista.El Comercio Lima 17 de diciembre. Recuperado de http://www.librosperuanos.com/autores/articulo/00000001701/Nace-unnovelista

Genette, G. (1989). Figuras III. Barcelona: Lumen.

Gutiérrez, M. (2007). La narrativa de la guerra 1980-2006. Libros y Artes, 20/21, pp. 18- 21.

Osorio, J. (2002). La narrativa andina. Sieteculebras, 16, pp. 6-10.

Oyarzún, K. (1993). Literaturas heterogéneas y dialogismo genérico-sexual. Revista de Crítica Literaria Latinoamericana, 38, pp. 37-50.

Pajuelo, R. (2012). “Una etnografía visual de la violencia peruana: horror y esperanza en los retablos de la colección Edilberto Jiménez". En Jurgen Golte y Ramón Pajuelo (eds.), Universos de memoria. Aproximaciones a los retablos de Edilberto Jiménez sobre la violencia política (pp. 34-44). Lima: Instituto de Estudios Peruanos. 
Pérez, J. (2004). Retablo. Lima: Editorial Universitaria Universidad Nacional Federico Villarreal.

Pérez, E. (2011). Racionalidades en conflicto: Cosmovisión andina (y violencia política). En Rosa Cuchillo de Óscar Colchado. Lima: Pakarina.

Rèmond, R. (2007). "La transmisión de la memoria". En Academia Universal de las culturas, ¿Por qué recordar? (pp.69-72).Argentina: Gránica.

Rivera, S. \& Barragán, R. (eds.) (1997). Debates postcoloniales. Una introducción a los estudios de subalternidad. La Paz: SEPHIS-Aruwiyiri.

Rivera, S. (2006). Chhixinakas utxiwa. Una reflexión sobre práctica y discursos descolonizadores. En Mario Yapu, Modernidad y pensamiento decolonizados. Memoria del Seminario Internacional (pp.3-16).

Sánchez, M. (2011). Del testimonio y sus implicaciones. Periferia,15, pp.1-19.

Sansón, J. (2007). "La biblioteca, memoria del porvenir". En Academia Universal de las culturas, ¿Por qué recordar? (pp.61-65). Argentina: Gránica.

Tolentino, C. (2014). El goce no solo es placer sino también dolor. Una charla con Julián Pérez Huarancca. Revista Buen Salvaje, 14-15.Recuperado de https:// revistabuensalvaje.wordpress.com/2014/03/18/el-goce-no-solo-es-placersino-tambien-dolor/

Thompson, J. (1998). Los media y la modernidad. Una teoría de los medios de comunicación. Barcelona: Paidós. 